\title{
TRANSFORMAR LA HETEROGENEIDAD EN RECURSO COMPARATIVO: VARIACIONES ETNOGRÁFICAS E HISTÓRICAS EN LOS SENTIDOS DE HOMOSEXUALIDAD Y FAMILIA
}

\section{Guido Vespucci ${ }^{1}$}

\section{Introducción $^{2}$}

Como bien sabemos, las investigaciones académicas no surgen de la nada sino de un plan o proyecto enmarcado en un campo especializado que las evalúa y habilita. Quiero comenzar señalando esto porque, aunque parezca obvio, la experiencia de hacer este tipo de pesquisa conlleva la responsabilidad de cumplir con determinadas exigencias y expectativas que se anuncian justamente en los proyectos de investigación. Es allí donde queda "oficialmente sellado el contrato", es decir, donde queda manifestado el compromiso con los pares expertos, con el campo científico y social del que se trate y, también, con uno mismo en tanto investigador comprometido con su tema. No obstante, también sabemos que los proyectos no son la investigación sino apenas una guía u hoja de ruta para comenzarla y eventualmente desarrollarla en el mediano o largo plazo. Así y todo, ¿cómo desarrollaríamos una investigación profesional sin contar con esa guía? Si traigo esto a colación en este artículo no es para hacer una reflexión sobre las normas del campo científico, sino para enmarcar de la manera más completa posible - desde su gestación en un plan - la experiencia de transitar los desafíos e imponderables que se presentan generalmente en cualquier investigación académica y transmitir parte de los sentidos de esa experiencia en el caso particular de mi última pesquisa.

Sobre lo que quería insistir es que, estén bien, regular o mal formulados, los proyectos de investigación suelen suponer algún grado de "idealización" de la pesquisa que vamos a desarrollar, aún se trate de aproximaciones inductivas más que hipotético deductivas $^{3}$. Se tiene, al menos, una expectativa de lo que se pretende descubrir y

\footnotetext{
${ }^{1}$ Consejo Nacional de Investigaciones Científicas y Técnicas (CONICET) - Universidad Nacional de Mar del Plata (UNMdP); Argentina.

${ }^{2}$ Una primera versión de este trabajo fue presentada en las I Jornadas de Jóvenes Investigadores del Centro de Estudios Históricos, Facultad de Humanidades, Universidad Nacional de Mar del Plata, 20-22 de noviembre de 2013.

3 Estoy empleando la noción de "idealización" para evitar una extensa y compleja discusión sobre las diferencias entre los enfoques inductivos e hipotético-deductivos. Simplemente diré que su inevitabilidad común a ambas aproximaciones no tiene, sin embargo, el mismo tratamiento y riesgo epistemológico, ya
} 
aportar ("hipótesis" y objetivos), el sentido o relevancia de ese supuesto aporte (inserción del problema en el marco de un campo de discusiones teóricas) y de cómo vamos a lograr esos objetivos (metodología y fuentes). En particular, la relación entre metodología y fuentes es más compleja de lo que parece, y de lo que se suele exigir en un proyecto sólido de investigación, esto es, con alto grado de factibilidad. Ateniéndonos a las investigaciones que implican algún grado de exploración empírica, diseñamos una metodología pensando en el tipo de fuentes de información con que contaremos, y en el mejor de los casos podremos llegar a disponer de "todo ese material" y/o de "todos los contactos necesarios" antes de comenzar su análisis. ¿Pero cómo saber que esas fuentes e informantes que ya ubicamos son suficientes para sustentar nuestro problema - y en el mejor de lo casos "demostrar nuestra hipótesis" - si todavía no los hemos analizado/explorado/entrevistado, al menos en su totalidad? ¿Cómo sabemos que esas fuentes e informantes no nos van a llevar a la búsqueda de más o distintas fuentes e informantes? Y, por ende, ¿cómo podemos asegurarnos que no necesitaremos de otras herramientas metodológicas no previstas para las fuentes de información imprevistas?

Estos imponderables de la investigación social son la contracara de aquella planificación e idealización. Mientras más e intensos sean los imponderables, más vertiginoso puede ser el derrumbe de las expectativas fundantes. Pero si de estos imponderables están hechas las investigaciones, el problema no es evitarlos, o disimularlos, sino hacerles el lugar que corresponde e intentar resolverlos.

$\mathrm{Si}$ hay alguna disciplina que conoce mejor que ninguna otra sobre estos imponderables es, creo yo, la antropología social con su enfoque etnográfico, y claramente inductivo ${ }^{4}$. Los antropólogos saben cuándo o dónde comienza "el campo" pero (saben que) desconocen cuándo o dónde termina. Y esto no sólo porque esté en juego un trabajo de interpretación y re-interpretación en la obtención de los datos ${ }^{5}$, el que permite el acceso a un nuevo conocimiento o a una nueva reflexividad (Guber, 2001), sino además porque desde que la visión clásica de cultura ha sido cuestionada en

que mientras en el primer caso "esa idealización" es apenas un disparador investigativo, controladamente transitoria, en el segundo tiene un fundamento más relevante, a la vez que puede llegar a representar un sesgo teórico poco controlado o directamente etnocéntrico.

4 Afirmación que no pretende ser "de manual" sino el producto de haber transitado mi formación académica y haber tenido experiencias de investigación en los campos de la historia, en parte de la sociología y finalmente en la antropología social.

${ }^{5}$ En esto no difiere o no debería diferir de otras disciplinas que usan un enfoque interpretativo. 
la antropología, ya no sabemos con una certeza anticipada dónde empieza la cultura y dónde termina, así como cuándo ha comenzado. Es decir, al pensar la cultura no como un sistema plenamente integrado, homogéneo y con contornos herméticamente sellados, sino como una lógica de producción, circulación y reapropiación de significados, diferencias y desigualdades en un mundo cada vez más interconectado, las (supuestas) fronteras originarias se desdibujan o difuminan a la vez que se multiplican las fronteras "internas" o zonas de cruce cultural (García Canclini, 2004). Algunas de las implicancias que tiene este reacomodo conceptual en términos metodológicos es que, así como el modelo teórico del "archipiélago cultural" se ha complejizado, la imagen del trabajo de campo como gran viaje e inmersión en un territorio delimitado y preciso ya no nos devuelve la certeza o la comodidad de capturar un objeto circunscrito o un sujeto colectivo inequívoco. En cambio, la modalidad de investigación etnográfica que habilita la conciencia de transitar un mundo altamente dinámico e interconectado mediante la circulación de objetos, símbolos y personas, requiere de "una etnografía móvil que toma trayectorias inesperadas al seguir formaciones culturales a través y dentro de múltiples sitios de actividad" (Marcus, 2001: 111). Del mismo modo en que esta modalidad investiga y construye los mundos de vida de varios sujetos situados, también construye etnográficamente aspectos de marcos sociales más amplios y procesos culturales macro, a través de conexiones y asociaciones que aparecen sugeridas en las localidades o en los mismos sujetos localizados.

En consecuencia, antes que la metáfora inmóvil de la "carpa estacada" de la etnografía clásica, tenemos en juego la metáfora del viaje continuo, o permanentes "encuentros de viaje" (Clifford, 1999), la que implica seguir a las personas y sus biografías, seguir términos y símbolos, seguir las tramas de sentido y sociabilidad, seguir la(s) historia(s) (Marcus, 2001). Es probable que al transitar ese viaje espaciotemporal, nuestros objetos previamente diseñados puedan sufrir alteraciones, ramificaciones y contrastes inesperados, y que tras ese repentino desdibujamiento de objeto experimentemos la incómoda sensación de estar frente a una mera sumatoria de datos inconexos, dispersos o heterogéneos. Sostengo que un buen instrumento analítico para volver fructíferos ese tipo de imponderables de la investigación etnográfica dinámica y multisituada - actualmente poco abordado en términos teóricos - son las comparaciones "al estilo Fredrik Barth", como mostraré a continuación respecto al 
rendimiento que ha tenido esa perspectiva analítica para enriquecer mi objeto de estudio $^{6}$.

En síntesis, en este artículo pretendo reflexionar acerca de cómo resolví determinados imponderables o dificultades teórico-metodológicas derivadas del trabajo de campo que permitieron concretar mi tesis doctoral titulada como Familia(s) y Homosexualidad(es): una exploración etnográfica e histórica por sus diversas relaciones (Vespucci, 2013) ${ }^{7}$, de la que seleccionaré algunas referencias de contenido para dicho cometido. La finalidad de estas reflexiones consiste entonces en poder detectar y dimensionar las potencialidades de las comparaciones como una aproximación metodológica en particular que - siguiendo la propuesta analítica de Barth - amerita ser revisada al calor de los debates antropológicos que suscita el concepto cultura para interpretar las sociedades contemporáneas.

\section{Del problema de la heterogeneidad hacia la formulación de un campo de variaciones}

Inicialmente, mi investigación de tesis tenía como objeto abordar etnográficamente las dinámicas relacionales desenvueltas en núcleos familiares constituidos por parejas del mismo sexo (y/o personas de orientación homosexual) y sus hijos/as, es decir, lo que usualmente fue conocido como "familias homoparentales" (Cadoret, 2003). Accedí a ese universo viajando desde mi ciudad de origen (Mar del Plata) a la ciudad de Buenos Aires para hacer observación participante en una serie de eventos públicos relacionados con las demandas de reconocimiento social de las familias homoparentales impulsados por el activismo $\mathrm{LGBT}^{8}$, en los que justamente asistían mujeres lesbianas que habían sido madres o que querían serlo. Pasado determinado lapso temporal, en el que realizaba observaciones y entrevistas etnográficas sobre sus respectivas familias en la ciudad de Buenos Aires, surgió la primera dificultad de campo ante el hecho - imprevisto - de no poder acceder a un mayor número de mujeres que se inscribieran en esa tipología familiar (parejas

\footnotetext{
${ }^{6}$ Agradezco al Dr. Federico Neiburg el haberme hecho revalorizar ese instrumento analítico en el marco de su seminario de Antropología Comparativa impartido en 2009 para el Doctorado en Antropología Social, Universidad Nacional de San Martín.

${ }^{7}$ Esta tesis aun no ha sido publicada en su totalidad, pero citaré algunos artículos que son producto de la misma para invitar a quienes estuvieran interesados en conocer parte de sus resultados.

${ }^{8}$ Lesbianas, gays, bisexuales y trans.
} 
lesbianas con hijos/as) ${ }^{9}$. Es necesario contextualizar esa dificultad de acceso dado que esas entrevistas se desarrollaron durante el año 2008, período en el que las relaciones homoeróticas, y en especial las familias homoparentales, eran bastante invisibles en comparación con la acelerada visibilización que trajo aparejado el debate social por la Ley de Matrimonio Igualitario, sancionada a mediados de $2010^{10}$. Sumemos a esto el plus de no pertenecer a la comunidad estudiada $\mathrm{y}$ - correlativamente - la entendible desconfianza de ciertas organizaciones del movimiento LGBT en brindar información a "foráneos" en un contexto en el que no había ninguna garantía social ni legal respecto a esas configuraciones familiares.

Con cierta ingenuidad, decidí continuar la exploración en Mar del Plata - ciudad en la que resido ${ }^{11}$ - intentando alivianar una inversión de tiempo y recursos que había dado sus frutos pero que ahora se mostraba inconducente. Pues bien: ¿y dónde estaban las "madres lesbianas" en Mar del Plata? Sólo hacia el final de la investigación logré acceder a algunas de ellas, ya que el panorama de invisibilidad era aún más acuciante que en Buenos Aires. No había aquí organización gay-lésbica alguna con la que yo pudiera entrar en contacto para allanar mi pesquisa (por eso la ingenuidad antes señalada). Recuerdo aquel momento como el de una crisis del proyecto de investigación y el consecuente ¡derrumbe de mis expectativas!

Sin mucha convicción, decidí explorar la problemática de la familia en varones homosexuales, a quienes accedí más rápidamente en Mar del Plata gracias a un informante clave que trabajaba "en el ambiente gay"12 y que tenía numerosos conocidos dentro y también fuera de ese ambiente. Pero las dificultades no terminaban ahí, porque mientras la mayoría de las mujeres lesbianas entrevistadas eran madres, la mayoría de mis informantes varones no eran padres ${ }^{13}$. En consecuencia, se abría el interrogante

\footnotetext{
${ }^{9}$ Había explorado seis configuraciones familiares de este tipo. No precisamente por un afán cuantitativo de representatividad, sino porque originalmente ese era mi objeto y percibía insuficiente lo obtenido para una tesis doctoral, es que insistía en incorporar más casos.

${ }^{10}$ La sanción de esta nueva ley que permite el casamiento a las parejas del mismo sexo fue antecedida de una intensa polémica que involucró no sólo a las élites políticas e intelectuales sino a amplísimos sectores sociales, produciendo un efecto de visibilización de la homosexualidad sin precedentes.

${ }^{11}$ Mar del Plata es una ciudad costera ubicada a $400 \mathrm{Kmts}$ al sur de la ciudad de Buenos Aires (capital federal de Argentina) y posee una población estimada en 800.000 habitantes.

${ }^{12}$ Término nativo que alude a un circuito de sociabilidad homoerótica que en Mar del Plata era bastante reducido, hermético e integrado principalmente por varones.

${ }^{13}$ Es decir, no sólo no encontraba más familias con madres lesbianas sino que al pasar al universo de los varones, se me desdibujaba el objeto específico originario, puesto que aquí estaba ausente la paternidad.
} 
imprevisto de saber cómo podía operar allí la noción de familia, si es que tenía algún asidero en términos nativos.

Prácticamente en simultáneo, permanecía latente otra incomodidad sobre el objeto que se desprendía de una observación de campo. En el año 2007, mientras comenzaba mis exploraciones, se presentaba en la sede porteña de la Asociación Psicoanalítica de Argentina (APA) el libro Homoparentalidades: nuevas familias (Rotenberg y Agrest Wainer, 2007) ${ }^{14}$. La presentación estuvo a cargo de un prestigioso activista de la Comunidad Homosexual Argentina $(\mathrm{CHA})^{15}$, quien, entre otras cosas, cuestionó en el título de la obra la noción nuevas familias, arguyendo que no eran "nuevas", sino en todo caso "visibles". En esa dirección, sostuvo: "los homosexuales siempre tuvimos familias", enunciado que volví a escuchar en reiteradas oportunidades, y sobre el que volveré más adelante. Si bien parece una simple anécdota de campo, la misma logró interpelarme de manera intensa. Mientras yo investigaba las familias homoparentales (personificadas por aquellas "lesbianas madres"16) como nuevas familias, me encontraba con que los referentes del activismo se molestaban por esa adjetivación, argumentando que los homosexuales siempre habían tenido familias. ¿Qué significado podía tener esa advertencia? ¿Se trataba de que había estado investigando ingenuamente un fenómeno como emergente cuando no lo era? Pues dicha afirmación contradecía, por un lado, el supuesto originario de este campo de estudios relativo a la novedad de las familias constituidas por personas homosexuales, al menos desde sus componentes de homoconyugalidad, homoparentalidad y - sobre todo - en su combinatoria $^{17}$, así como en la atribución de un claro sentido de familia a tales prácticas

\footnotetext{
${ }^{14}$ Cuyas autoras pertenecen al campo psicoanalítico. Como mostré en mi tesis (Vespucci, 2013), los saberes psi funcionaron como un destacado catalizador en los debates sobre homoparentalidad, ya sea para legitimar o impugnar estas configuraciones familiares, según sus distintos posicionamientos teóricos e ideológicos.

${ }^{15}$ La CHA es una de las organizaciones de reivindicación de derechos para personas homosexuales de mayor trayectoria y peso político en Argentina, surgida en 1984 y continúa hasta el presente.

${ }^{16}$ Con ese término se autodefinían algunas de esas mujeres, ponderando el hecho de haberse asumido primero como "lesbianas" y luego como "madres", distinguiéndose así tanto de las "madres heterosexuales" como de las mujeres que se asumieron lesbianas después de haber sido madres en el marco de uniones heterosexuales.

${ }^{17}$ Términos provenientes de la literatura académica de Brasil y Francia respectivamente; en especial el segundo tuvo bastante difusión en Argentina. Así, el concepto de "homoconyugalidad" hace referencia a una ética conyugal estable u ordenada en el marco de vínculos de pareja de personas del mismo sexo, (Saraiva Paiva, 2007); mientras que el de "homoparentalidad" refiere al ejercicio de la pater/maternidad de personas de orientación homosexual (Cadoret, 2003). Cuando designo conjuntamente ambas configuraciones suelo utilizar el término familias diversas o sencillamente familias homosexuales, y cuando quiero problematizar los sentidos nativos sobre familia tiendo a utilizar el concepto de arreglos intimos o domésticos, según el caso.
} 
y estructuras. Y por otro, esa información se desdibujaba ante ciertas evidencias históricas. En efecto, dado que comenzaba a interesarme por el rol de las organizaciones LGBT respecto al problema de la familia en la homosexualidad, entre otros habían llegado a mis manos, casi fortuitamente, algunos documentos de la década del setenta pertenecientes al Frente de Liberación Homosexual de Argentina (FLH) ${ }^{18}$. Nada semejante a un reclamo familiarista se derivaba de ese movimiento social - sino exactamente todo lo contrario - ni tampoco que el ambiente homosexual de la época tuviera prácticas homoeróticas conceptualizables fácilmente como familias, o un lenguaje familiarista para interpretar dichas prácticas.

Es decir que en esa etapa de la investigación tenía un conjunto de datos heterogéneos - cuando no inconmensurables, llegué a pensar - que trascendían mi original objeto en términos sincrónicos como diacrónicos. Respecto al primer eje (sincrónico), mi material de campo contenía, por una parte, configuraciones domésticas integradas por parejas de lesbianas que eran madres, de clase media y con experiencias directas de activismo lésbico o un capital cultural familiarizado con el mismo, residentes en Buenos Aires. Por otra parte, un mapa variado de configuraciones íntimas y domésticas integrado por parejas de gays sin hijos que convivían y que no convivían, gays que convivían con parientes o amigos, o que vivían solos, de clase media baja y sin experiencias de activismo gay o con un capital cultural menos asociado al modelo gay que a los modelos de la privacidad y bio-psi ${ }^{19}$, residentes en Mar del Plata.

Respecto al segundo eje (diacrónico), por un lado se me imponían continuamente nuevas informaciones relativas a los reclamos de reconocimiento familiar de parte de las organizaciones LGBT de mi presente etnográfico, cristalizados

${ }^{18}$ El FLH fue una de las organizaciones más radicalizadas en la historia de los movimientos de reivindicación homosexual de Argentina, surgido en 1971 y disuelto a raíz de la dictadura militar de 1976.

${ }^{19}$ Dado que los modelos culturales sobre la homosexualidad no son infinitos sino esquemáticamente tres (modelo bio-psi, modelo de la privacidad y modelo gay-lésbico), el contraste social que importa entre estos grupos de mujeres y varones homosexuales radica, antes que en la clase en sentido estrictamente económico, en el tipo de capital cultural y sus correlativas tramas de sociabilidad (enmarcadas según lugar de residencia) que los acercan o alejan de cada modelo. Utilizo entonces modelo gay-lésbico para aquellas personas que poseen identificaciones positivas de su orientación (homo)sexual y que tienden a reivindicarla públicamente. Por su parte, el modelo bio-psi (que pivotea entre lo congénito y lo adquirido) tiende a proveer percepciones más problemáticas o directamente negativas (patológicas) de su orientación (homo)sexual; mientras que el modelo de la privacidad implica una ética de discreción sobre la misma. Estos modelos no deben comprenderse como realidades empíricas puras, sino como tipos ideales al estilo weberiano - orientando prácticas y percepciones en los actores - que pueden aparecer de forma hibridada, como una impronta bio-psi que se vea resignificada y valorizada positivamente bajo el modelo gay, o una ética de discreción que opere para encubrir valoraciones negativas del modelo bio-psi. 
en figuras legales como el matrimonio y acompañados por discursos como el de "somos familias" o "nuestras familias" (Vespucci, 2014). Y por el otro, datos históricos que desdibujaban ese marco interpretativo familiarista a medida que me alejaba en el tiempo, a punto tal de localizar discursos claramente anti-familiaristas.

Esas cuatro dimensiones constituían básicamente el cuadro de heterogeneidad que me devolvía no precisamente mis objetivos y búsquedas focalizadas en el campo, sino mi tránsito por el mismo, en el cual mi sensación era que a medida que más lo transitaba, más se diversificaba. En definitiva: ¿tenía en juego una o cuatro tesis?, pues bien podría haber intentado profundizar una sola de esas dimensiones y escoger así una de esas cuatro tesis posibles. Pero creo que por fortuna localicé una aproximación teórico-metodológica que me permitió no sólo incrementar y capitalizar los datos disponibles, sino además intentar aportar a los encendidos debates sobre el reconocimiento de la homosexualidad y sus familias desde un lugar de restitución de coordenadas diacrónicas y sincrónicas, es decir, desde una contextualización sociotemporal del objeto en debate.

En efecto, las polémicas intra y extra-académicas desatadas a partir de los reclamos de reconocimiento social-legal sobre la homoconyugalidad y la homoparentalidad, estaban atravesadas por la urgencia de la agenda política, lo que volvía frecuentes afirmaciones reificadas y poco analíticas como: "los homosexuales siempre tuvieron un estilo de vida opuesto a la familia", "las familias homosexuales son idénticas o una copia de las familias heterosexuales", "los homosexuales siempre tuvieron familias"; por no señalar las afirmaciones más crudamente ideológicas: "los homosexuales no deberían reclamar la familia ni figuras como el matrimonio", "los homosexuales deberían reclamar la familia y el matrimonio como cualquier ciudadano". La heterogeneidad de mis datos me permitía trascender y a la vez contextualizar ese tipo de afirmaciones esencialistas, que pretendían instalar una verdad sobre el auténtico "estilo de vida homosexual".

¿Cuál era entonces esa aproximación que estaba empezando a intervenir en mis preguntas de investigación? Por un lado, el cuestionamiento a determinadas visiones clásicas del concepto cultura, esto es, la idea de cultura como sistema holístico, integrado, homogéneo y estático (a-histórico), en el cual ciertos aspectos observables se vuelven el fundamento estructurante - y por tanto explicable - de una cultura (Barth, 2000; Rosaldo, 1991; Bensa, 1998). En mi objeto de estudio, estos principios bien 
podían traducirse y aplicarse al (menos clásico) concepto de subcultura o, incluso, al de identidad en su versión "externalista" (Brubaker y Cooper, 2002), es decir, como “imputación identitaria". De ahí, el denominador común de "los homosexuales son...". Pero cuáles (o quiénes), dónde, desde cuándo, en qué contextos, eran dimensiones que no entraban dentro de esos principios de afirmación o afirmaciones principistas, probablemente porque también volvieran más complejos y menos evidentes los embates políticos de la agenda.

No se trataba, como en otros cuestionamientos radicales a la noción clásica de cultura, de negar toda su capacidad analítica, desconociendo cualquier nivel de significación compartida entre los actores (Abu-Lughod, 2005). Si la cultura no es un sistema homogéneo e integrado de normas y valores, tampoco se desintegra en una sumatoria de individuos, pues "no tenemos tantos universos simbólicos como personas" (Grimson \& Semán, 2005: 15). Sino que de lo que se trata, es de advertir que "los actores están posicionados" de manera diferente y desigual (Barth, 2000: 128 ${ }^{20}$, 136138; Fonseca, 2005) respecto a determinados significantes que circulan y significados que se intentan imponer socialmente. Ello implica que "la cultura es distributiva", compartida por algunos actores y no por otros ${ }^{21}$, y que "el significado es una relación, (...) entre un signo y un observador" (Barth, 2000: 128-136), y no una entelequia expresada como propiedad de un sistema holístico e integrado. Entonces, la pregunta de mi investigación ya no era cómo son los homosexuales y cuál es su "estilo de vida" (concepto que muchas veces ha servido más para reificar/esencializar/homogeneizar que para restituir los contextos de sus particularidades), sino cómo cuestionan, negocian, apropian o reproducen ciertos actores ${ }^{22}$ en un tiempo y escenario determinado, nociones de homosexualidad y familia, y cómo ello les habilita y/o condiciona determinadas prácticas homoeróticas y familiares.

\footnotetext{
${ }^{20}$ Todas las traducciones de la obra de Barth citadas en el presente artículo son mías.

${ }^{21}$ Para ser más precisos, hay que aclarar que "la perspectiva distribucional afirma que si bien los grupos no tienen rasgos culturales absolutamente homogéneos, tampoco podría afirmarse que los rasgos están aleatoriamente distribuidos", por lo que es posible delimitar contornos en los que la cultura se comparte (Grimson, 2011: 142). Y por otro lado, esta afirmación tampoco implica que una serie de rasgos culturales compartidos determine las mismas identificaciones en todos los actores. Por el contrario, distintas identidades pueden pertenecer a una misma cultura, en la que a pesar de esas diferencias identitarias los actores reconozcan una trama de sentidos que los envuelve, atributos comunes que los caracterizan, y visualicen sus fronteras simbólicas respecto a otra configuración cultural que les resulte ajena (Grimson, 2011).

${ }_{22}$ Con perfiles socioculturales diferentes pero que tienen en común una orientación (homo) sexual.
} 
Sin embargo, estas entradas analíticas no eran "una teoría (preconcebida) de la cultura", sino derivaciones teóricas habilitadas por el prisma de los datos de campo. Y en rigor de verdad, fueron un punto de enlace y de llegada más que de partida. En efecto, como ya mencioné, en determinada instancia de la investigación yo no veía más que dispersión y heterogeneidad de datos. Fue precisamente el enlace entre esa heterogeneidad y dichas premisas teóricas el que me abriría otra puerta para pensar en una y no cuatro tesis diferentes. Es decir, se jugaba ahí la posibilidad de capitalizar y aportar algo desde esa dispersión y heterogeneidad. No obstante, esto no responde cómo fue esa operación, cuál fue la metodología que vehiculizó ese enlace empírico-teórico, esto es, cómo se llegó a decantar esa tesis y no otras.

La clave en este sentido, fue convertir la dispersión y heterogeneidad de datos en recurso comparativo. Es así que decidí apostar a una herramienta metodológica típica (aunque algo olvidada o invisibilizada ${ }^{23}$ ) de la disciplina antropológica, pero reformulada en relación a esas "nuevas premisas" de la cultura. Aunque hay escaso consenso sobre cómo deben realizarse comparaciones en el campo de la antropología, su uso histórico más común ha sido espejo de las comparaciones en el área de las ciencias naturales. En la "anatomía comparada", la operación principal es la identificación de estructuras equivalentes, o sea, partes de dos o más organismos o especies diferentes que puedan ser comparadas. Traducido a la antropología, eso ha implicado comparaciones de (descripciones de) diversas estructuras sociales, sistemas simbólicos o culturas a partir de la semejanza o diferencia de sus respectivos patrones estructurales y de la función de sus instituciones (Barth, 2000: 188, 189). No estoy sugiriendo que dichas comparaciones sean a priori espurias, pero si coincidimos en que delimitar culturas es bastante más complejo que escoger organismos o especies, esto es, si volvemos a las premisas relativas a "la naturaleza continua de la variación de la cultura" (Ingold en Barth, 2000: 195) por sobre las premisas de la cultura como sistema herméticamente sellado, homogéneo, estático e integrado, entonces las comparaciones “entre culturas" corren el riesgo de ciertas arbitrariedades ${ }^{24}$. Por consiguiente, es preciso

\footnotetext{
${ }^{23}$ Por invisibilizada quiero decir que muchas investigaciones se desenvuelven utilizando el recurso comparativo pero sin que se reconozcan explícita o concientemente como investigaciones comparativas.

${ }^{24}$ Las que pueden incrementarse, dirá Barth (2000: 189, 190), si tenemos en cuenta que no son comparaciones directas sobre el objeto (como en las ciencias naturales) sino comparaciones de descripciones, es decir, realizadas con posterioridad al trabajo de campo. Esto supone, al menos potencialmente, problemas del orden de la inconmensurabilidad de lo comparado, derivados de todos los
} 
invertir o desarmar ese orden analítico, de la distinción entre "el análisis de las formas internas a un conjunto de datos de campo y las comparaciones trans-culturales hechas entre tales unidades" (Barth, 2000: 191).

Esto es lo que propone, o mejor dicho hace, Fredrik Barth en algunas de sus investigaciones, como por ejemplo, cuando analiza los rituales de las comunidades Baktaman de Nueva Guinea. En principio comenzó investigando en una comunidad Baktaman, pero la participación en su vida y en sus actividades lo llevó a visitar lugares próximos a esa comunidad, no necesariamente dominados por los Baktaman pero que eran parte de la construcción de su mundo. Fue más lejos aún, dice Barth, y extendió su campo a regiones más alejadas de su visión del mundo, donde recogía informaciones sobre los Baktaman. Mediante ese proceso, Barth consiguió "percibir la utilidad analítica de la variación: la diferencia y la diversidad pueden ser conceptualmente transformadas en un campo de variabilidad, llevando progresivamente a la construcción de un conjunto de dimensiones de variación para facilitar la descripción de cualquier forma observada" (2000: 193). La apuesta por las variaciones de y sobre los rituales Baktaman le permitió obtener, a fin de cuentas, una mayor perspectiva analítica sobre dicho objeto. E inclusive, teniendo en cuenta que esa perspectiva también le habilitaba observar características que tendían a la covariación, advertir que lo que parecían datos totalmente inconexos podían ser interdependientes.

Es así que, frente a la percepción de datos heterogéneos y dispersos, me apropié del "principio metodológico barthiano" concerniente a la búsqueda de variaciones de un mismo objeto/problema, o dicho de otro modo, que la clave metodológica era que el nuevo problema se constituía a partir de las variaciones del objeto. Esto implicaba explicitar que mi búsqueda iba tejiendo un campo de variaciones y redoblar la apuesta en esa dirección, destrabando así el momento de suspense por detenerme frente a lo heterogéneo y, en cambio, otorgarle una intencionalidad que habilite dicho registro. En este sentido, "el método comparativo" no fue un ejercicio posterior a la delimitación y descripción de distintos focos empíricos o aspectos del objeto - como lo hubiera hecho una comparación de la antropología clásica - sino un ejercicio simultáneo al trabajo de campo, una herramienta metodológica constitutiva en la creación del objeto/problema. En consecuencia, el problema que guió la investigación pasó a redefinirse como la

imponderables del trabajo de campo $\mathrm{y}$, correlativamente, de las parcialidades inevitables a toda descripción. 
exploración etnográfica e histórica de diversas maneras en que se relacionan nociones y prácticas de homosexualidad y familia. Es decir, variaciones de esa relación entre distintos (perfiles de) actores, escenarios sociales y períodos históricos.

\section{Algunos resultados de las variaciones}

Para expresar y conceptualizar dichas variaciones utilicé una suerte de metáfora química, es decir, la homosexualidad y la familia como "componentes" de diversas "fórmulas" - desde ya, simbólicas - según distintos contextos históricos y (perfiles de) actores sociales. Así, la tesis permite mostrar que en el contexto de las décadas 60 y 70 estuvieron en juego una fórmula impensable y otra indeseable de articular ambas nociones. En efecto, para un importante segmento de personas homosexuales era impensable porque, entre otras razones, sus prácticas homoeróticas en ese período tendían a desarrollarse en un ambiente urbano clandestino que habilitaba encuentros sexuales fugaces ${ }^{25}$ - y muchas veces violentos - entre "locas" y "chongos"26, condicionando la posibilidad de mantener relaciones afectivas. Transitoriedad, clandestinidad, violencia, homofobia, eran características antagónicas a las de amor, estabilidad, convivencia, matrimonio, parentalidad, que caracterizaban la idea de familia, ciertamente indisociable del universo heterosexual. El término "impensable" aparece como categoría nativa esbozada desde un presente etnográfico en el que precisamente la articulación simbólica y práctica entre homoerotismo y familia se ha vuelto pensable $\mathrm{y}$ posible, connotando inversamente su imposibilidad $\mathrm{e}$ incompatibilidad hacia los años 60 y 70 . En este sentido, la idea de que "los homosexuales siempre tuvieron familias" es una forma de anacronismo ${ }^{27}$.

\footnotetext{
${ }^{25}$ Dado que las fuentes de las que disponemos refieren a lo que sucedía en los circuitos de ambiente, circunscribimos nuestro análisis a ese escenario - mayormente transitado por varones. De todas maneras, conjeturo que era bastante improbable que hubiera muchas personas que lograran mantener prácticas o relaciones homoeróticas por fuera del mismo, ya que justamente transitar los circuitos de ambiente permitía deducir (y concretar) la existencia del deseo homoerótico, y a la vez protegerlo u ocultarlo de las sanciones morales y legales imperantes en una sociedad heteronormativa.

${ }^{26}$ Mientras el perfil de "loca" o "marica" performaba una identidad genérica femenina, el perfil del "chongo" performaba una marcada masculinidad, al punto de que su temor a ser identificado como marica (homosexual) podía implicar prácticas violentas hacia las locas.

${ }^{27}$ Es probable que esa idea enunciada frecuentemente en el discurso activista ("los homosexuales siempre tuvimos familias") tuviera antes que nada una connotación política, esto es, la de legitimar (aunque fuera bajo cierto anacronismo) la emergencia de familias homosexuales y sus respectivos reclamos de reconocimiento social y legal. Por otro lado, no he hallado registros para este período como para advertir que la idea de familia estuviera operando para dar sentido a posibles vínculos de amistad entre
} 
Por su parte, dicha articulación fue indeseable porque el FLH, en su intento por representar aquel ambiente homoerótico, elaboró un marco interpretativo cuya consigna central suponía que para "liberar la homosexualidad" era necesaria "la muerte de la familia" (Vespucci, 2011). Dicho marco fue una elaboración interdiscursiva a partir de corrientes de pensamiento características del clima contestatario de la época, tales como el freudiano-marxismo, la antipsiquiatría y el feminismo anti-patriarcal. Mediante esas claves, la familia fue entendida como uno de los engranajes fundamentales desde donde operaba la "represión sexual" - en directa correlación con un sistema capitalista que extraería esa "energía reprimida" para canalizarla hacia el trabajo alienado - y la homosexualidad como portadora de un potencial de "liberación sexual y social". Se comprende entonces que miradas bajo ese lente interpretativo, ambas nociones se rechazaran mutuamente, constituyendo una fórmula indeseable.

Así, explorar las nociones de homosexualidad y familia que operaron en otro contexto histórico me permitió dimensionar mejor el carácter emergente que observaba en mi presente etnográfico respecto a su reconfiguración simbólica. Dicho pasado, después de todo, no era una elección caprichosa, sino que se derivaba al seguir las pistas de campo que provenían de las mismas operaciones comparativas que hacían algunos actores, justamente aquellos que por su rango etario y trayectoria de vida estaban experimentado el contraste entre haber vivenciando el homoerotismo bajo las reglas del sexo ocasional y clandestino - repudiando ideológicamente la moral (hetero)sexual de la familia en tanto miembros del FLH - y poder advertir ahora la formación de familias integradas por homosexuales; entre haber sido parte de un colectivo sufriente y estigmatizado en "el período homosexual", y el de disponer del acceso a los derechos civiles del "período gay" (Meccia, 2011).

En esta clave histórica, la tesis evidencia un lento cambio social por medio de la formación de prácticas y sentidos familiares tanto en determinados segmentos del universo homosexual como desde la creación de un marco interpretativo familiarista por parte de los nuevas organizaciones LGBT hegemónicas. En consecuencia, la constitución de familias integradas por madres lesbianas evidencia una fórmula

homosexuales, como es el caso del "parentesco por elección” de las comunidades gay-lésbicas en Estados Unidos (Weston, 2003), sino que como ya señalé, la idea de familia se circunscribía al universo heterosexual, seguramente por el peso de simbologías como el matrimonio y la consanguinidad en la cultura familiar iberoamericana. Como se verá más adelante, dichas simbologías de parentesco permanecen en el imaginario de muchos homosexuales hasta nuestro presente, al igual que lo han mostrado otras investigaciones en España (Pichardo, 2009). 
emergente de articular prácticas y nociones de homosexualidad y familia. Por su parte, el discurso "somos familias" y el reclamo por el "matrimonio igualitario" son la condensación cultural y legal de ese proceso de articulación simbólica que se resume en una fórmula deseable de relacionar ambas nociones ${ }^{28}$.

Al mismo tiempo, la tesis deja ver determinados momentos de suspense, conflictos y permanencias de determinados modos de vida homosexuales dentro de ese proceso de cambio. Así, se observa que el marco interpretativo familiarista finalmente dominante en los colectivos LGBT no siempre fue evidente, consensuado, ni es extensivo a todos los segmentos homosexuales. Desde aquella fórmula indeseable hasta esta fórmula deseable domina (sobre todo entre principios de los 80 y mediados de los 90) una fórmula en suspenso que revela tensiones y disputas representacionales en los colectivos gay-lésbicos entre considerar la homosexualidad como un "estilo de vida" singular basado en las prácticas de sexo ocasional, o comprender la pre-emergencia de algunas prácticas (formación de parejas estables, convivencia, nociones de amor romántico, entre otras) como portadoras de un sentido familiar ${ }^{29}$. Son esas mismas tensiones las que permanecen en determinados segmentos homosexuales (en mi registro de campo coincidentes con varones del perfil ya señalado) que encuentran incompatibles o contradictorios sus variados arreglos íntimos y domésticos (parejas sin hijos que conviven y que no conviven, gays que conviven con parientes o amigos, o que viven solos) con el discurso dominante "somos familias", y de allí la idea de fórmulas diversas y liminales de articular ambas nociones.

Aquí la idea de esta diversidad no tiene que ser entendida necesariamente al igual que la consigna o concepto de "familias diversas" que ha sido frecuente en el discurso activista e incluso académico para significar que no hay una sola manera de conformar familias y que los homosexuales pueden tener, y de hecho tienen, familias. Sino que pretende evidenciar que también hay actores que consideran que sus arreglos domésticos no se adecuan a las convenciones sociales de lo que significa "tener una

\footnotetext{
${ }^{28}$ Considero que el desafío abierto para este campo de estudios consiste en explorar y evaluar el impacto de la Ley de Matrimonio Igualitario en las prácticas y representaciones de diversos segmentos del universo homosexual, más allá de su notable repercusión política y simbólica recientes. En esa dirección está planteada mi investigación posdoctoral, y sus primeros resultados podrán verse en (Vespucci, 2015en prensa).

${ }^{29}$ El concepto de pre-emergencia alude a la gestación de prácticas sociales que no poseen un modelo cultural preestablecido para ser interpretadas o codificadas. De allí que en ese momento tales prácticas no tuvieran una clara traducción como símbolos de familia. Agradezco al Dr. Ignacio Pichardo el haberme sugerido la utilidad de dicho concepto, cual fuera empleado en su investigación sobre familias diversas en España (2009).
} 
familia", generalmente porque asocian esta institución al universo heterosexual. Cuando esa percepción rige las prácticas de los actores de manera más o menos voluntaria, he conceptualizado dichos arreglos domésticos como diversos. En cambio, cuando los actores expresan su deseo de lo que entienden como "familia", pero a la vez viéndose a sí mismos condicionados o limitados en las posibilidades de su consecución, he optado por denominar sus arreglos como liminales. El concepto de liminalidad es precisamente una manera de traducir conceptualmente esa tensión que experimentan los actores entre su tipo ideal de familia y las configuraciones domésticas que ellos logran conformar con sus prácticas.

Como se ve, las comparaciones analíticas pueden ser muchas veces un enlace teórico de las comparaciones que realizan los propios actores para percibirse a sí mismos y posicionarse ante otros. Si muchos de los varones homosexuales se comparaban desfavorablemente respecto a un tipo ideal de familia - la familia nuclear heterosexual con hijos - devolviéndoles un semblante melancólico a sus relatos biográficos, varias de las parejas lesbianas que convivían en núcleos familiares homoparentales, se comparaban favorablemente respecto al modelo estándar de familia (Bestard, 2009). Y es que el ethos militante que las caracterizaba - de cuño lésbico y feminista - les devolvía una imagen desafiante, y a veces superadora, de sus propios arreglos domésticos frente a la heteronormatividad familiar. En efecto, no sólo habían construido una identidad sexual positiva y politizada, "el lesbianismo", sino que además habían trasgredido los condicionamientos sociales, culturales y legales que históricamente han legitimado el modelo estándar de familia (heterosexual), al inscribirse en una ideología igualitaria (o anti-patriarcal) de la pareja, al plantearse y concretar sus maternidades desde una orientación sexual asumida socialmente como no reproductiva, al proyectar la educación de sus hijos/as bajo los valores de "la tolerancia" o "la diversidad sexual", al desafiar los mandatos heterosexistas de sus familias de origen, entre otros aspectos, todos ellos percibidos como rupturas con el orden familiar heteronormativo. Entonces, lejos de comprender a sus familias como una copia o asimilación a la norma (hetero)familiar en razón de su semejanza estructural, las prácticas y sentidos atribuidos a las mismas están cimentadas en la singularidad de su identidad sexual, distinguiéndose del modelo estándar de familia. Por el contrario, otras mujeres homosexuales que bajo la misma composición familiar no destacaban particularmente su identidad sexual - más allá de si el término nativo para 
autodesignarse fuera lesbiana, homosexual o gay - tendían a diluir cualquier diferencia sustancial con respecto a las familias heterosexuales convencionales, y a percibirse "como cualquier familia", como "una familia normal". Al mismo tiempo, aquellas mujeres que se inscribían en un ethos militante del lesbianismo y la familia lésbica, se comparaban y distinguían de las familias de otras mujeres homosexuales que eran madres, ya sea porque estas maternidades habían sido producto de parejas heterosexuales previas a la salida del armario, porque reprodujeran supuestamente roles estereotipados de género, entre otras razones. Así, algunas de ellas dejaban en claro que su identidad no era la de "madres" o "madres lesbianas", sino "lesbianas madres", destacando las etapas de su itinerario biográfico, primero la de asumirse como lesbianas, y a partir de ahí planificar la maternidad.

Podría continuar mostrando contrastes y matices en los significados atribuidos a las nociones de homosexualidad y familia, pero a los fines de mi argumento creo que es suficiente. Lo que he querido demostrar es el rendimiento de haber apostado a la exploración de variaciones etnográficas e históricas para poder complejizar y profundizar el problema de mi tesis doctoral. En efecto, la exploración de esas variaciones ha permitido restituir algunos contextos particulares de sentido allí donde otros discursos sociales (fueran activistas, legos o expertos) tendieron a descuidar las singularidades históricas y a aplanar las diferencias sincrónicas.

\section{Consideraciones finales}

Finalmente, entre otros aspectos de mi tesis doctoral, la exploración de variaciones del mismo problema (diversos modos de articular nociones de homosexualidad y familia) me permitió mostrar a las personas que comparten una orientación (homo)sexual no como miembros de "un estilo de vida" estático, integrado y homogéneo, es decir, como una (sub)cultura en el sentido clásico del término, sino como actores posicionados en un campo de producción de sentidos y prácticas (respecto a la homosexualidad y la familia) que tienden a variar ligera o drásticamente según determinadas coordenadas diacrónicas y sincrónicas. $\mathrm{Y}$ esa dimensión de mi investigación fue posible gracias a un trabajo de campo dinamizado por la aproximación comparativa. 
Visto en perspectiva - como decimos aquí, "con el diario del lunes" - puede resultar obvio que las prácticas y sentidos relativos a la homosexualidad y la familia no sean uniformes si tomamos en cuenta variables como el escenario social, el contexto histórico y el perfil o trayectoria de los actores. Sin embargo, lo que quiero destacar es que dicha heterogeneidad no siempre era evidente en este campo de estudios e inquietudes sociales, atravesado por las ansiedades políticas de las disputas por la representación legítima del "auténtico modo de vida homosexual". Pero más importante aún para esta reflexión teórico-metodológica, es el hecho de que la apuesta por las variaciones y el recurso comparativo no fue algo premeditado ni automático. Si bien dicha orientación se imponía frente a la dispersión y heterogeneidad de datos, implicó además un ejercicio de reflexividad, o dicho de otra manera, transitar un proceso que incluyó momentos de crisis en la viabilidad de mi problema originario de estudio, pausas reflexivas y replanteos de objeto, para finalmente adoptar un posicionamiento teórico-metodológico particular y una toma de decisiones en el trabajo de campo.

Uno se podría preguntar, ¿qué resultados habría obtenido si mi decisión hubiera sido seleccionar alguna de esas cuatro tesis probables, tratando de "homogeneizar" todo lo posible mi objeto/sujeto de estudio? Apostar obstinadamente al encuentro de un sujeto/objeto homogéneo - sean familias homosexuales, heterosexuales o rituales Baktaman - con tal de ganar seguridad teórica (e ideológica) en virtud de haber capturado (y eventualmente representado) una cultura, segmento o grupo, conlleva el riesgo de invisibilizar las variaciones de la cultura, y la tentación de elaborar apresuradas sinécdoques que deriven una totalidad cultural de apenas una parte de sus componentes, una clásica operación del culturalismo antropológico mediante la apelación al terreno de "lo simbólico". Porque "el culturalismo proviene de esa homogeneización de principio que transforma las prácticas singulares en signos pertinentes de un conjunto" (Bensa, 1998: 65). Si no debiera haberse aplicado este principio si quiera a las "culturas exóticas o primitivas", menos productivo puede ser ante los procesos de intensa circulación de signos, personas e hibridación de sentidos que caracteriza un mundo cada vez más interconectado y a la vez fragmentado en múltiples "paisajes culturales" (Appadurai, 2001), ya que "el argumento que identifica sin intermediarios la parte con el todo, no introduce una reflexión sobre las incidencias empíricas y teóricas de las variaciones de escala" (Bensa, 1998: 65). 
De ningún modo estoy diciendo con esto que contextualizar, historizar y desesencializar implique que se disuelva la noción de cultura. Los procesos de desterritorialización, hibridación y heterogeneidad que dificultan la vieja utopía antropológica de encontrar una cultura o el grupo en su sentido clásico (homogéneo, integrado, estático, delimitado, casi esencial) conviven con procesos de reterritorialización, formación de patrones, atributos o tramas de sentido compartidas y sus matrices de heterogeneidad específicas que restituyen la posibilidad de capturar una configuración cultural con sus respectivas fronteras simbólicas. El punto es que esas tramas, matrices y fronteras no están al alcance de la mano, no están preestablecidas a los ojos del investigador, porque no se deducen mecánicamente de apenas un atributo cultural (sea de clase, raza, religión u orientación sexual), como tampoco garantizan el acceso a una identidad ${ }^{30}$. En esta dirección, las investigaciones etnográficas multisituadas y procesuales que persiguen o atienden las variaciones de la cultura pueden ser un horizonte antropológico interesante frente a las dinámicas que nos imponen las sociedades contemporáneas. Las metodologías comparativas, como el uso de las variaciones "al estilo Barth", constituyen una herramienta privilegiada para tal fin.

\footnotetext{
${ }^{30}$ Es decir, la manera en que los actores se piensan, ubican, sienten y narran a sí mismos - se identifican en relación a esas tramas de sentido que los envuelve o configuración cultural a la que pertenecen. Una traducción empírica de la distinción analítica entre configuración cultural e identidad implicaría señalar, por ejemplo, que en Argentina el peso del discurso familiarista del movimiento LGBT hegemónico y su efecto legal ha instalado un marco de sentido y posibilidades para repensar la modalidad en que los homosexuales pueden relacionarse y a los derechos a los que pueden aspirar (como el de casarse y formar una familia). Pero ese marco de posibilidades más o menos reconocido por todos, tiene distintas intensidades o capacidades de interpelación en los actores según sus trayectorias, experiencias, intereses, edades, tramas de sociabilidad específicas, generando más "empatía" o más "distancia" en relación al mismo, o en su extremo, habilitando identificaciones "a favor" o "en contra", ya que además convive con otros discursos sobre la homosexualidad y la familia sedimentados históricamente (el de los saberes psi, el de las religiones, el de la "privacidad", el de la "liberación sexual", etc.). La evidencia más contundente de la productividad de esta distinción analítica radica en advertir que el hecho de compartir algunos atributos y prácticas (tener una orientación homosexual, conformar una familia homoparental, casarse) no garantiza una "equivalencia identitaria" respecto a cómo interpretar, sentirse y expresarse en torno a estas nuevas posibilidades culturales y legales. Para profundizar en la distinción conceptual entre configuración cultural e identidad, véase (Grimson, 2011).
} 


\section{Referencias}

ABU-LUGHOD, Lila. "La interpretación de la(s) cultura(s) después de la televisión". Etnografías contemporáneas, año 1, nº 1, Buenos Aires. 2005.

APPADURARI, Arjun. La modernidad desbordada. Dimensiones culturales de la globalización. Buenos Aires, Fondo de Cultura Económica. 2001.

BARTH, Fredrik. O guru, o iniciador e outras variações antropológicas. Río de Janeiro, Contracapa. 2000.

BENSA, Alban. "Da micro-história a uma antropologia crítica". En Jacques REVEL (org.) Jogos de escalas. A experiência da microanálise. Río de Janeiro, Editoria Fundação Getulio Vargas. 1998.

BRUBAKER, Rogers y COOPER, Frederick. "Más allá de 'identidad". Apuntes de Investigación $\mathrm{n}^{\circ}$ 7, Buenos Aires. 2002.

CADORET, Anne. Padres como los demás. Homosexualidad y parentesco. Barcelona, Gedisa. 2003.

CLIFFORD, James. Itinerarios transculturales. Barcelona, Gedisa. 1999.

FONSECA, Claudia. "La clase social y su recusación etnográfica". Etnografías contemporáneas, año 1, $\mathrm{n}^{\circ}$ 1, Buenos Aires. 2005.

GARCÍA CANCLINI, Néstor. Diferentes, desiguales y desconectados. Mapas de la interculturalidad. Barcelona, Gedisa. 2004.

GRIMSON, Alejandro. Los límites de la cultura: crítica de las teorías de la identidad. Buenos Aires, Siglo XXI Editores. 2011.

GRIMSON, Alejandro y SEMÁN, Pablo. "Presentación: la cuestión cultura". Etnografías contemporáneas, año 1, $\mathrm{n}^{\circ}$ 1, Buenos Aires. 2005.

GUBER, Rosana. La etnografía: método, campo y reflexividad. Bogotá, Editorial Norma.

MARCUS, George E. 2001. "Etnografía en/del sistema mundo: el surgimiento de la etnografía multilocal". Alteridades vol. 11, nº 22. 2001.

MECCIA, Ernesto. Los últimos homosexuales. Sociología de la homosexualidad y la gaycidad. Buenos Aires, Gran Aldea Editores. 2011.

PICHARDO, José I. Entender la diversidad familiar. Relaciones homosexuales y nuevos modelos de familia. Barcelona, Bellaterra. 2009.

ROSALDO, Renato. Cultura y verdad. México, Grijalbo. 1991.

ROTENBERG, Eva y AGREST WAINER, Beatriz (comps.). Homoparentalidades: nuevas familias. Buenos Aires, Lugar Editorial. 2007.

SARAIVA PAIVA, Antônio C. "Reserva e invisibilidade: a construção da homoconjugalidade numa perspectiva micropolítica”. En Miriam GROSSI, Anna P. UZIEL y Luiz MELLO (orgs.), Conjugalidades, parentalidades, e identidades lésbicas, gays e travestis, Río de Janeiro, Garamond, pp. 23-46. 2007.

VESPUCCI, Guido. "Explorando un intrincado triángulo conceptual: homosexualidad, familia y liberación en los discursos del Frente de Liberación Homosexual de Argentina (FLH, 19711976)". Historia Crítica no 43, pp. 174-197. 2011. Disponible en:

http://dx.doi.org/10.7440/histcrit43.2011.10

VESPUCCI, Guido. "Familias diversas en Argentina: antes y después del matrimonio igualitario". En Rosa PARISI (comp.), Famiglie, omosessualità, genitorialità: pratiche e narrazioni del vivere assieme, SEID editoripublicazione [en prensa]. 2015.

VESPUCCI, Guido. Familia(s) y homosexualidad(es). Una exploración etnográfica e histórica por sus diversas relaciones. Tesis de Doctorado en Antropología Social defendida en el 
Instituto de Altos Estudios Sociales (IDAES), Universidad Nacional de San Martín (UNSAM). 2013.

VESPUCCI, Guido. "Una fórmula deseable: el discurso 'somos familias' como símbolo hegemónico de las reivindicaciones gay-lésbicas". Revista Latinoamericana de Sexualidad, Salud y Sociedad no 17. 2014. Disponible en:

http://www.e-publicacoes.uerj.br/index.php/SexualidadSaludySociedad/article/view/6413/9553

WESTON, Kath. Las familias que elegimos. Lesbianas, gays y parentesco. Barcelona, Bellaterra. 2003.

Recebido em: 26/03/2015

Aprovado em: 23/05/2015 